\title{
Systemic Lupus Erythematosus and Psoriasis: A Case Report
}

Jaouad Yousfi $^{1 *}$, Soukaina Oumlil ${ }^{1}$, Laila Benjilali ${ }^{1}$, Lamiaa Essaadouni ${ }^{1}$

${ }^{1}$ Department of Internal Medicine, University Hospital of Mohammed VI, Marrakesh, Morocco

\section{Article History \\ Received: 27.01.2021 \\ Accepted: 10.03.2021 \\ Published: 13.03.2021 \\ Journal homepage: \\ https://www.easpublisher.com}

Quick Response Code

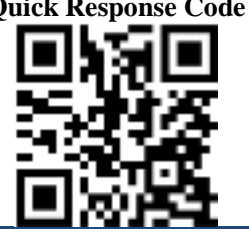

Copyright $(02021$ The Author(s): This is an open-access article distributed under the terms of the Creative Commons Attribution 4.0 International License (CC BY-NC 4.0) which permits unrestricted use, distribution, and reproduction in any medium for non-commercial use provided the original author and source are credited.

\section{INTRODUCTION}

Psoriasis is a chronic-recurrent inflammatory disease which affect $1-3 \%$ of general populations [1-3]. It is a progressive erythemato-squamous dermatitis of unknown etiology. Psoriasis can be aggressive by developing arthropathy, erythrodermic or pustulosis forms. The etiopathogenesis of psoriasis is not completely understood. Genetic, immunologic and environmental factors have been suggested [4]. Systemic lupus erythematosus (SLE) is an autoimmune disease with a broad spectrum of manifestations, from localized cutaneous lesions (acute, subacute, and chronic) with a benign course, to a rapidly progressive and fatal systemic illness [3, 5]. The prevalence of SLE has been estimated from 14.6 to 122 cases per 100,000 [6, 7].

Although SLE has been described in association with other autoimmune diseases such as rheumatoid arthritis, scleroderma, mixed connective tissue disease, autoimmune thyroid diseases and pernicious anemia [8], its coexistence with psoriasis is very rare $[9,10]$. This association is very challenging due to the similarity of the clinical features (cutaneous and articular), but also due to the difficulty of its management, since medications used to treat one condition can exacerbate or even trigger the symptoms of the other $[1-4,6,10,11]$.

\section{CASE PRESENTATION}

A 43-year-old woman, with a history of a wellcontrolled type 2 diabetes mellitus for 13 years on premixed insulin and glimepiride at a dose of $3 \mathrm{mg} /$ day, and hypothyroidism treated by thyroid hormone replacement therapy (Levothyroxine $100 \mu \mathrm{g} /$ day), presented to the hospital with ery the matous- squamous plaques localized over the scalp and extensor surfaces of the elbows and knees. The diagnosis of psoriasis was made based on typical clinical findings and a skin biopsy.

The patient received methotrexate, and achieved complete remission after six months. One year after the diagnosis of psoriasis, the patient presented with drug-resistant chronic headache, alopecia, photosensitivity, malar rash and polyarthralgia involving knees, wrists and elbows.

The results of laboratory tests included an erythrocyte sedimentation rate of $60 \mathrm{~mm}$ in the first hour, C-reactive protein of $70 \mathrm{~g} / \mathrm{dl}$.

Serum anti-nuclear antibodies were positive with a titer of $1 / 640$ and a homogeneous pattern. The titer of anti-dsDNA was high at $40 \mathrm{IU} / \mathrm{ml}$.

Kidney function was normal and proteinuria was $0.1 \mathrm{~g} / 24 \mathrm{~h}$. A brain MRI showed micro nodular white matter lesions. 
The patient also presented with chest tightness and dyspnea (NYHA class II) due to interstitial lung disease.

Infection workup, for lung involvement, was negative (Genexpert and cyto-bacteriological examination of the sputum). The electrocardiogram and the echocardiogram were normal.

The diagnosis of SLE with cutaneous, articular, neurologic and pulmonary involvement was established, and the patient was started on low-dose corticosteroid therapy. She also received cyclophosphamide for theneurological and pulmonary involvement. The cumulative dose received was $12 \mathrm{~g}$.

After 5 years of follow-up, complete remission was achieved; SLE remained clinically quiescent, and no exacerbation of psoriatic skin lesions was observed.

\section{DISCUSSION}

The coexistence of psoriasis with SLE has been reported in the literature $[4,6,12]$. A studillo reported psoriasis in $0.6 \%$ of 520 patients with SLE [13]. Other series respectively collected ten cases over 25 years [6]; five cases over ten years [4] and three cases over seven years [14]. Zalla and Muller identified 42 cases of SLE among 9420 psoriasis patients in a 10year retrospective study [4]. The prevalence rate of psoriasis coexisting with SLE is around $1.1 \%$, slightly higher in women, due to the higher prevalence of SLE in this population [15].

The pathogenesis of this association is not fully understood, as theunderlying autoimmune mechanism is still unknown. Dysregulation of the immune response and $\mathrm{T}$ cell activation by superantigens appear to be the common pathogenetic mechanism of these two pathologies [2, 12], as does mutations in the human leukocyte antigen (HLA) gene [14]. However, psoriasis and SLE can appear independently in the same patient, without necessarily having a causal relationship between them [1].

These patientsseem to have an increased risk for photosensitivity and anti-SSA antibodies [4, 14]. According to Kullick et al., [14], the presence of antiSSA antibodies would be a serological marker suggestive of the SLE - Psoriasis association. However, they are not always present, and some authors reported the coexistence of the two conditions in the absence of anti-SSA antibodies [10, 13, 16]. Additionally, antiSSA antibodies may be positive in some patients with psoriasis without such an association [17]. Sulphasalazine and phototherapy (Psoralen and ultraviolet-A (UV-A) light) for psoriasis has been linked to SLE development in isolated cases [13, 14, 18, 19]. Thus, Kullick et al., recommend testing for antiSSA antibodies in psoriasis patients before starting phototherapy. Their positivity would contraindicate the treatment with UV-A rays [14].

The coexistence of SLE and psoriasis was reported without contributing factors [20], notably drug intake $[4,6]$. In our case, the patient developed SLE after psoriasis although she didn't receive phototherapy and tested negative for anti-SSA antibodies.

This coexistence is a therapeutic challenge since antimalarial drugs (chloroquine and hydroxychloroquine), which are fundamental in SLE treatment, may induce or exacerbate psoriatic skin lesions $[13,21]$. This drug would be responsible for severe forms of psoriasis; erythrodermic and pustular [22]. It could lead to its development in patients with a family history of psoriasis, or exacerbate pre-existing psoriatic lesions; but they would not induce the disease. The aggravating role ofantimalarial drugs is reported in more than $18 \%$ of cases; they would have a nonspecific role in the stimulation of epidermal proliferation [23]. However, extension of the psoriatic lesions is only noted in 6.5 to $18 \%$ of cases with psoriatic arthritis treated by antimalarial drugs [24, 25].

In addition, prolonged corticosteroid therapy would lead to the development of generalized pustular and erythrodermic forms [26].

Methotrexate seems to be the drug of choice in SLE associated with extensive psoriasis worsened by antimalarial drugs and/or by the reduction of corticosteroids [27]. It should be introduced at a low weekly dose as soon as the corticosteroid tapering is initiated. Its effectiveness is indisputable since complete remissions are noted in $60 \%$ of cases [28]. The side effects of methotrexate are dominated by hepatotoxicity and hematotoxicitywarranting regular clinical and laboratory monitoring [27].

\section{CONCLUSION}

Psoriasis and systemic lupus erythematosus are relatively common diseases in the population but their association is rare. Their coexistence poses a diagnostic and therapeutic challenge to the clinician. Therapeutic choices need careful consideration to avoid the exacerbation of any of these diseases.

\section{REFERENCES}

1. da Silva, R. S., do Nascimento, L. B., Bressan, A. L., Obadia, D., \& Gripp, A. C. (2014). Psoríase fotossensível como um alerta para o diagnóstico lúpus eritematoso sistêmico. Medicina cutánea iberolatino-americana, 42(1), 46-49.

2. Avriel, A., Zeller, L., Flusser, D., Shakra, M. A., Halevy, S., \& Sukenik, S. (2007). Coexistence of psoriatic arthritis and systemic lupus erythematosus. IMAJ-RAMAT GAN-, 9(1), 48. 
3. Kim, E. J., Park, H. S., Yoon, H. S., \& Cho, S. (2015). A case of psoriasis accompanied by systemic lupus erythematosus. Annals of dermatology, 27(3), 347.

4. Zalla, M. J., \& Muller, S. A. (1996). The coexistence of psoriasis with lupus erythematosus and other photosensitive disorders. Acta dermatovenereologica. Supplementum, 195, 1-15.

5. Brenol, J. C. T., Santiago, M. B., Szajubok, J. C. M., Rachid-Filho, A., Barros, R. T., \& Vasconcelos, M. (2006). Lúpus Eritematoso Sistêmico: Acometiment Acometimento Cutâneo/Articular. Rev Assoc Med Bras, 52(6), 375-88.

6. Millns, J. L., \& Muller, S. A. (1980). The coexistence of psoriasis and lupus erythematosus: an analysis of 27 cases. Archives of dermatology, 116(6), 658-663.

7. de Matos Prado, D., Amaral, B. A., Duarte, S. F. P., do Vale, A. E., Silva, M. L., Rocha, A. R., \& Sousa, V. M. (2017). Perfil dos Pacientes portadores de Lúpus Eritematoso Sistêmico atendidos pelo Componente Especializado da Assistência Farmacêutica em uma Regional de Saúde. ID on line Revista De Psicologia, 11(38), 808-823.

8. Lorber, M., Gershwin, M. E., \& Shoenfeld, Y. (1994, October). The coexistence of systemic lupus erythematosus with other autoimmune diseases: the kaleidoscope of autoimmunity. In Seminars in arthritis and rheumatism (Vol. 24, No. 2, pp. 105113). WB Saunders.

9. Lynch, W. S., \& WS, L. (1978). Lupus erythematosus and psoriasis vulgaris.

10. Hays, S. B., Camisa, C., \& Luzar, M. J. (1984). The coexistence of systemic lupus erythematosus and psoriasis. Journal of the American Academy of Dermatology, 10(4), 619-622.

11. Baselga, E., Puig, L., Llobet, J., Musulén, E., \& de Moragas, J. M. (1994). Linear psoriasis associated with systemic lupus erythematosus. Journal of the American Academy of Dermatology, 30(1), 130-133.

12. Wielosz, E., Majdan, M., Żychowska, I., \& Jeleniewicz, R. (2008). Coexistence of five autoimmune diseases: diagnostic and therapeutic difficulties. Rheumatology international, 28(9), 919923.

13. Astudillo, L., Sailler, L., Carreiro, M., Dahan, S., \& Ollier, S. (2003). Psoriasis et lupus érythémateux disséminé: une association rare, des problèmes thérapeutiques spécifiques. In Annales de médecine interne (Paris) (Vol. 154, No. 1, pp. 3-6).

14. Kulick, K. B., Mogavero Jr, H., Provost, T. T., \& Reichlin, M. (1983). Serologic studies in patients with lupus erythematosus and psoriasis. Journal of the American Academy of Dermatology, 8(5), 631634.
15. Dadalto, K. P., Guimarães, L. G., \& Marchióri, K. C. P. (2019). Coexistence of vulgar psoriasis and systemic lupus erythematosus-case report. Rev Med (São Paulo), 98(1), 77-80.

16. Sezgin, A. O., Turk, B. G., \& Ertam, I. (2010). A case of psoriasis complicated with systemic lupus erythematosus. J Turk Acad Dermatol, 4(4), 04403c.

17. Janjumratsang, P., Phainupong, D., Chanjanakijskul, S., \& Roongphibulsopit, P. (2008). Positive direct immunofluorescence and autoantibody profiles in psoriasis patients. The Journal of dermatology, 35(8), 508-513.

18. Eyanson, S., Greist, M. C., Brandt, K. D., \& Skinner, B. (1979). Systemic lupus erythematosus: association with psoralen-ultraviolet-A treatment of psoriasis. Archives of dermatology, 115(1), 54-56.

19. Pirner, K., Rubbert, A., Salinger, R., Kalden, J. R., \& Manger, B. (1992). Significance of ultraviolet light in the pathogenesis of systemic lupus erythematosus: case report and discussion of the literature. Zeitschrift fur Rheumatologie, 51(1), 20-24.

20. Guilhou, J. J. (2000). Psoriasis: diagnostic et étiopathogénie. Encycl Méd Chir Dermatologie, 98190.

21. Abel, E. A., DiCicco, L. M., Orenberg, E. K., Fraki, J. E., \& Farber, E. M. (1986). Drugs in exacerbation of psoriasis. Journal of the American Academy of Dermatology, 15(5), 1007-1022.

22. Vine, J. E., Hymes, S. R., Warner, N. B., \& Cohen, P. R. (1996). Pustular psoriasis induced by hydroxychloroquine: a case report and review of the literature. The Journal of dermatology, 23(5), 357361.

23. Wolf, R., Matz, H., Marcos, B., \& Orion, E. (2005). Drug rash with eosinophilia and systemic symptoms vs toxic epidermal necrolysis: the dilemma of classification. Clinics in dermatology, 23(3), 311314.

24. Gladman, D. D., Blake, R., Brubacher, B., \& Farewell, V. T. (1992). Chloroquine therapy in psoriatic arthritis. The Journal of rheumatology, 19(11), 1724-1726.

25. Jajić, Z., Jajić, I., \& Grazio, S. (1995). Chloroquine in the treatment of psoriatic arthritis. Reumatizam, 42(2), 7-9.

26. Saurat, J. H., Lachapelle, J. M., Lipsker, D., \& Thomas, L. (2004). Dermatologie et infections sexuellement transmissibles. Elsevier Masson.

27. Goucha, S., Hamzaoui, S., Abdallah, M., Bouslama, K., Harmel, A., Ennafaa, M., ... \& Dridi, M. B. (2005). Association lupus érythémateux systémique et psoriasis. À propos d'une observation. La Revue de médecine interne, 26(5), 431-433.

28. Bournerias, I. (2004). Prescrire le methotrexate dans le psoriasis. Rev Prat, 54, 52-5.

Cite This Article: Jaouad Yousfi et al (2021). Systemic Lupus Erythematosus and Psoriasis: A Case Report. East African Scholars J Med Surg, 3(2), 41-43. 